\title{
Complete mitochondrial genome of Prismognathus prossi (Coleoptera: Lucanidae) with phylogenetic implications
}

\author{
Jing Liu, Yuyan Cao, Shiju Zhou, Yongjing Chen \& Xia Wan*
}

Liu, J., Cao, Y.Y., Zhou, S.J., Chen, Y.J. \& Wan, X. 2019: Complete mitochondrial genome of Prismognathus prossi (Coleoptera: Lucanidae) with phylogenetic implications. — Entomol. Fennica 30: 90-96. https://doi.org/10.33338/ef.82927

The complete mitochondrial genome of a Chinese stag beetle, Prismognathus prossi, was generated using the Illumina next-generation sequencing. The mitogenome sequence is $15,984 \mathrm{bp}$ in length, the nucleotide composition is A $36.6 \%$, C $17.5 \%$, T $34.3 \%$ and G $11.6 \%$ with the AT-content of $70.9 \%$. The sequence has similar features with other reported insect mitogenomes, consisting of 13 proteincoding genes (PCGs), 22 transfer RNA genes, two ribosomal RNAs and a control region. All of the protein-coding genes start with the typical ATN initiation codon except for COI. Maximum Likelihood (ML) and Bayesian Inference (BI) indicated that P.prossi share an affinity with Lucanus mazama, Lucanus fortunei and Cyclommatus vitalisi.

\begin{abstract}
J. Liu, Y.Y. Cao, S.J. Zhou, Y.J. Chen \& X. Wan, Department of Ecology, School of Resources and Engineering, Anhui University, Anhui, Hefei, 23000, China.

E-mails: Jing Liu: jj2641171265@163.com; Yuyan Cao: 1210252162@163. com; Shiju Zhou: 15056161961@126.com; Yongjing Chen: cyj1452394259 @163.com: Xia Wan (* corresponding author): wanxia@ahu.edu.cn
\end{abstract}

Received 28 February 2018, accepted 13 September 2018

\section{Introduction}

Insect mitogenome has been one of the most useful molecular markers and it has been widely applied to infer systematics at many taxonomic levels (Cameron 2014, Breeschoten et al. 2016, Timmermans et al. 2016, Li et al. 2017, Liu et al. 2017, López-López \& Vogler 2017). The number of sequenced mitochondrial genomes in Coleoptera are far from enough to clarify the biodiversity and complex evolutionary pathways between them (Gillett et al. 2014, Crampton-Platt et al. 2015, Timmermans et al. 2016, Yuan et al. 2016). In particular, complete mitogenomic data of Lucanidae is available for only few species despite their great evolutionary and systematic interest. So far, just 18 lucanid mitogenomes including seven complete ones have been reported
(Sheffield et al. 2009, Kim et al. 2013, Wu et al. 2016, Lin et al. 2017, Liu et al. 2017).

In this study, we sequenced the complete mitogenome of the lucanid Prismognathus prossi Bartolozzi \& Wan, 2006 for the phylogenetic studies. This species is easily recognized in the field by its impressive mandibles and canthus in males (Fig. 1). It is distributed in the southern China with limited records in provinces of Sichuan, Guizhou and Guangxi (Bartolozzi \& Wan 2006, Wan \& Yang 2007, Fujita 2010, Huang \& Chen 2017). Like many other stag beetles, $P$. prossi has also confronted habitat loss or fragmentation, global climate change and overhunting by enthusiasts and specimen merchants. The mitogenomic data is not indispensable only for understanding the systematics of Lucanidae, but it could also provide the basic genetics infor- 
Table 1. Primers and their sequences used in this study for Prismognathus prossi.

\begin{tabular}{llll}
\hline Gene & Primer name & Sequence $\left(5^{\prime}-3^{\prime}\right)$ & Reference \\
\hline COI & COI-F1 & CAACATTTATTTTGATTTTTTGG & Simon et al. 1994 \\
& COI-R1 & TCCAATGCACTAATCTGCCATATTA & \\
Cytb & Cytb-F2 & GAGGAGCAACTGTAATTACTAA & Balke et al. 2004 \\
& Cytb-R2 & AAAAGAAARTATCATTCAGGTTGAT & \\
rRNA-L & 16 SF1 & CCGGTTTGACTCAGATCATG & Hosoya et al. 2001 \\
& $16 S R 1$ & TAATTTATTGTACCTTGTGTATCAG & \\
\end{tabular}

mation for follow-up studies, and for formulating plans for assessing the conservation status of P. prossi throughout its range.

\section{Materials and methods}

\subsection{Sample collection and DNA extraction}

The voucher specimen of $P$. prossi was collected from Mt. Fanjingshan, Guizhou Province in $\mathrm{Au}-$ gust, 2014 by Yunfei Wu. It was deposited in the Museum of Anhui University. Total genomic DNA was extracted from the muscular tissue of P. prossi using the Qiagen DNAeasy Kit (Qiagen, Düsseldorf, Germany).

\subsection{Primer design, polymerase chain reaction, amplification and sequencing}

The complete mitogenome of $P$. prossi was assembled from amplified fragments with the primers listed in Table 1. The PCR amplifications were carried out in the volume of $25 \mu \mathrm{L}$ containing $1 \mu \mathrm{L}$ in $10 \mu \mathrm{M}$ of each primer (forward and reverse), $2 \mu \mathrm{L}$ template DNA, $12.5 \mu \mathrm{L} 2 \mathrm{X}$ EasyTaq SuperMix (+dye), and $8.5 \mu \mathrm{L}$ sterile double-distilled water. The PCR was performed under the following conditions: an initial denaturation at 94 ${ }^{\circ} \mathrm{C}$ for $2 \mathrm{~min}$, followed by 35-37 cycles of denaturation at $94{ }^{\circ} \mathrm{C}$ for $40 \mathrm{~s}$, annealing at $52-58{ }^{\circ} \mathrm{C}$ for $50 \mathrm{~s}$, and elongation at $70{ }^{\circ} \mathrm{C}$ for $1 \mathrm{~min}$, and then a final extension step at $72^{\circ} \mathrm{C}$ for $7 \mathrm{~min}$. The annealing temperature was determined by the length of the fragment. The sequencing was conducted with the Illumina HiSeq 2000 platform (BGI Genomics, Shenzhen, China).

The cluster strands created by the bridge am- plification were primed and all four fluorescently labeled and 3-OH-blocked nucleotides were added to the flow cell with DNA polymerase. The cluster strands were extended in single nucleotides. Following the incorporation step, the unused nucleotides and DNA polymerase molecules were washed away, a scan buffer added to the flow cell, then the optics system scanned each lane of the flow cell in imaging units (tiles). Once imaging was completed, chemicals that affect cleavage of the fluorescent labels and the $3-\mathrm{OH}$ blocking groups were added to the flow cell, which prepared the cluster strands for another round of fluorescent nucleotide incorporation.

\subsection{Mitogenome assembly, annotation and analysis}

The mitogenome of $P$. prossi was assembled using SOAP denovo (BGI Company, Shenzhen, China) and preliminary annotations were made with the MITOS WebServer (http://mitos.bioinf. uni-leipzig.de/index.py). Secondary structure of tRNA genes was inferred using tRNAscan-SE 2.0 (http://lowelab.ucsc.edu/tRNAscan-SE/). Those that were not identified by tRNAscanoSE, as well as $16 \mathrm{~S}$ ribosomal RNA ( $r R N A-L)$ and $12 \mathrm{~S}$ ribosomal RNA $(r R N A-S)$, were determined according to sequence similarity with related species.

The protein-coding genes (PCGs) were determined by ORF Finder (http://www.ncbi.nlm.nih. gov/gorf/gorf.html) under the invertebrate mitochondrial genetic code. The values of nucleotide composition, codon usage, and relative synonymous codon usage (RSCU) of PCGs were calculated with MEGA version 6.05 (Tamura et al. 2013). PCGs were translated with DNAMAN 
Table 2. Mitogenome organization of Prismognathus prossi.

\begin{tabular}{|c|c|c|c|c|c|c|c|}
\hline Gene & Strand & Region & $\begin{array}{l}\text { Length } \\
\text { (bp) }\end{array}$ & $\begin{array}{l}\text { Start } \\
\text { codon }\end{array}$ & $\begin{array}{l}\text { Stop } \\
\text { codon }\end{array}$ & $\begin{array}{l}\text { Anti- } \\
\text { codon }\end{array}$ & $\begin{array}{l}\text { Intergenic } \\
\text { nucleotides } \\
\text { (bp) }\end{array}$ \\
\hline trnl & $J$ & $1 \sim 64$ & 64 & - & - & GAT & -3 \\
\hline $\operatorname{trn} Q$ & $\mathrm{~N}$ & 62 130 & 69 & - & - & TTG & 3 \\
\hline $\operatorname{trnM}$ & $\mathrm{J}$ & 73 202 & 69 & - & - & CAT & 0 \\
\hline nad2 & $\mathrm{J}$ & $203 \sim 1216$ & 1,014 & ATC & TAA & - & 2 \\
\hline $\operatorname{trn} W$ & $\mathrm{~J}$ & $1022 \sim 1083$ & 65 & - & - & TCA & -8 \\
\hline $\operatorname{trn} C$ & $\mathrm{~J}$ & $1276 \sim 1335$ & 60 & - & - & GCA & 0 \\
\hline $\operatorname{trn} Y$ & $\mathrm{~N}$ & 1336 1398 & 63 & - & - & GTA & 1 \\
\hline $\operatorname{cox} 1$ & $\mathrm{~J}$ & $1400 \sim 2935$ & 1,536 & AAT & TAA & - & -5 \\
\hline $\operatorname{trn} L(C U N)$ & $\mathrm{J}$ & 2931 2995 & 65 & - & - & TAA & 0 \\
\hline $\operatorname{cox} 2$ & $\mathrm{~J}$ & 2996 3683 & 688 & ATA & $\mathrm{T}$ & - & 0 \\
\hline trnK & $J$ & $3684 \sim 3753$ & 70 & - & - & CTT & 0 \\
\hline $\operatorname{trn} D$ & $\mathrm{~J}$ & $3754 \sim 3816$ & 63 & - & _- & GTC & 0 \\
\hline atp8 & $\mathrm{J}$ & $3817 \sim 3972$ & 156 & ATT & TAA & - & -4 \\
\hline atp6 & $\mathrm{J}$ & $3975 \sim 4635$ & 661 & ATT & $\mathrm{T}$ & - & 0 \\
\hline $\cos 3$ & $\mathrm{~J}$ & $4657 \sim 5419$ & 784 & ATG & $\mathrm{T}$ & - & 0 \\
\hline $\operatorname{trn} G$ & $J$ & $5420 \sim 5481$ & 62 & - & - & TCC & -3 \\
\hline nad3 & $\mathrm{J}$ & 5479 5835 & 357 & ATA & TAG & - & -2 \\
\hline $\operatorname{trn} A$ & $\mathrm{~J}$ & 5834 5898 & 65 & - & - & TGC & -1 \\
\hline $\operatorname{trnR}$ & $\mathrm{J}$ & $5898 \sim 5961$ & 64 & - & _- & TCG & -1 \\
\hline $\operatorname{trnN}$ & $\mathrm{J}$ & $5961 \sim 6025$ & 65 & - & - & GTT & -1 \\
\hline $\operatorname{trn} S(A G N)$ & $\mathrm{J}$ & $6026 \sim 6092$ & 67 & - & - & $\mathrm{TCT}$ & 0 \\
\hline $\operatorname{trn} E$ & $\mathrm{~J}$ & $6093 \sim 6155$ & 63 & _- & _- & TTC & -2 \\
\hline $\operatorname{trn} F$ & $\mathrm{~N}$ & $6154 \sim 6216$ & 63 & - & - & GAA & -3 \\
\hline nad5 & $\mathrm{N}$ & $6214 \sim 7930$ & 1,717 & ATT & $\mathrm{T}$ & & 0 \\
\hline $\operatorname{trnH}$ & $\mathrm{N}$ & $7931 \sim 7993$ & 63 & - & - & GTG & -4 \\
\hline nad4 & $\mathrm{N}$ & $7990 \sim 9329$ & 1,340 & ATG & $\mathrm{T}$ & - & -7 \\
\hline nad4l & $\mathrm{N}$ & $9323 \sim 9610$ & 298 & ATG & TAA & - & 2 \\
\hline $\operatorname{trn} T$ & $\mathrm{~J}$ & $9613 \sim 9675$ & 63 & - & - & TGT & 3 \\
\hline $\operatorname{trn} P$ & $\mathrm{~N}$ & 9679 9740 & 62 & - & - & TGG & 4 \\
\hline nad6 & $\mathrm{J}$ & $9745-10227$ & 483 & ATG & TAA & - & -1 \\
\hline$c o b$ & $\mathrm{~J}$ & $10227 \sim 11369$ & 1,143 & ATG & TAG & - & 2 \\
\hline $\operatorname{trn} S(U C N)$ & $\mathrm{J}$ & 11368 11432 & 65 & - & & TGA & 19 \\
\hline nad1 & $\mathrm{N}$ & 11452 12405 & 954 & ATA & TAG & - & -3 \\
\hline $\operatorname{trn} L(C U N)$ & $\mathrm{N}$ & $12403 \sim 12465$ & 63 & - & - & TAG & 0 \\
\hline$r r n L$ & $\mathrm{~N}$ & $12466 \sim 13726$ & 1,261 & - & - & - & 1 \\
\hline $\operatorname{trnV}$ & $\mathrm{N}$ & $13728 \sim 13796$ & 69 & _- & - & TAC & -1 \\
\hline$r r n S$ & $\mathrm{~N}$ & 13796 14542 & 747 & - & - & - & 0 \\
\hline Control region & - & $14543 \sim 15984$ & 1,442 & - & _- & - & 0 \\
\hline
\end{tabular}

v7.0.2.176 (Lynnon Biosoft, Vaudreuil-Dorion, Canada). The mitogenome was mapped with CGView (Grant \& Stothard 2008). Composition skew analysis was conducted according to formulas AT skew $=[\mathrm{A}-\mathrm{T}] /[\mathrm{A}+\mathrm{T}]$ and $\mathrm{GC}$ skew $=$ $[\mathrm{G}-\mathrm{C}] /[\mathrm{G}+\mathrm{C}]($ Perna \& Kocher 1995).

\subsection{Phylogenetic analyses}

Phylogenetic analyses, based on 12 of the 13 protein-coding genes (for Aegus angustus, nad2 was not available), included the newly sequenced $P$. prossi and 18 other stag beetles from Genbank (Table 2) as well as three scarabid outgoup species. The model of nucleotide substitution was selected according to the Akaike Information Criterion (AIC) with jModelTest v2.1.4 (Posada 2008). Phylogenetic trees based on GTR + I + G model were generated via ML analysis using RAxML (Stamatakis 2014) and Bayesian inference (BI) with MrBayes v3.2.5 (Huelsenbeck \& Ronquist 2003). Node supports in the ML tree 


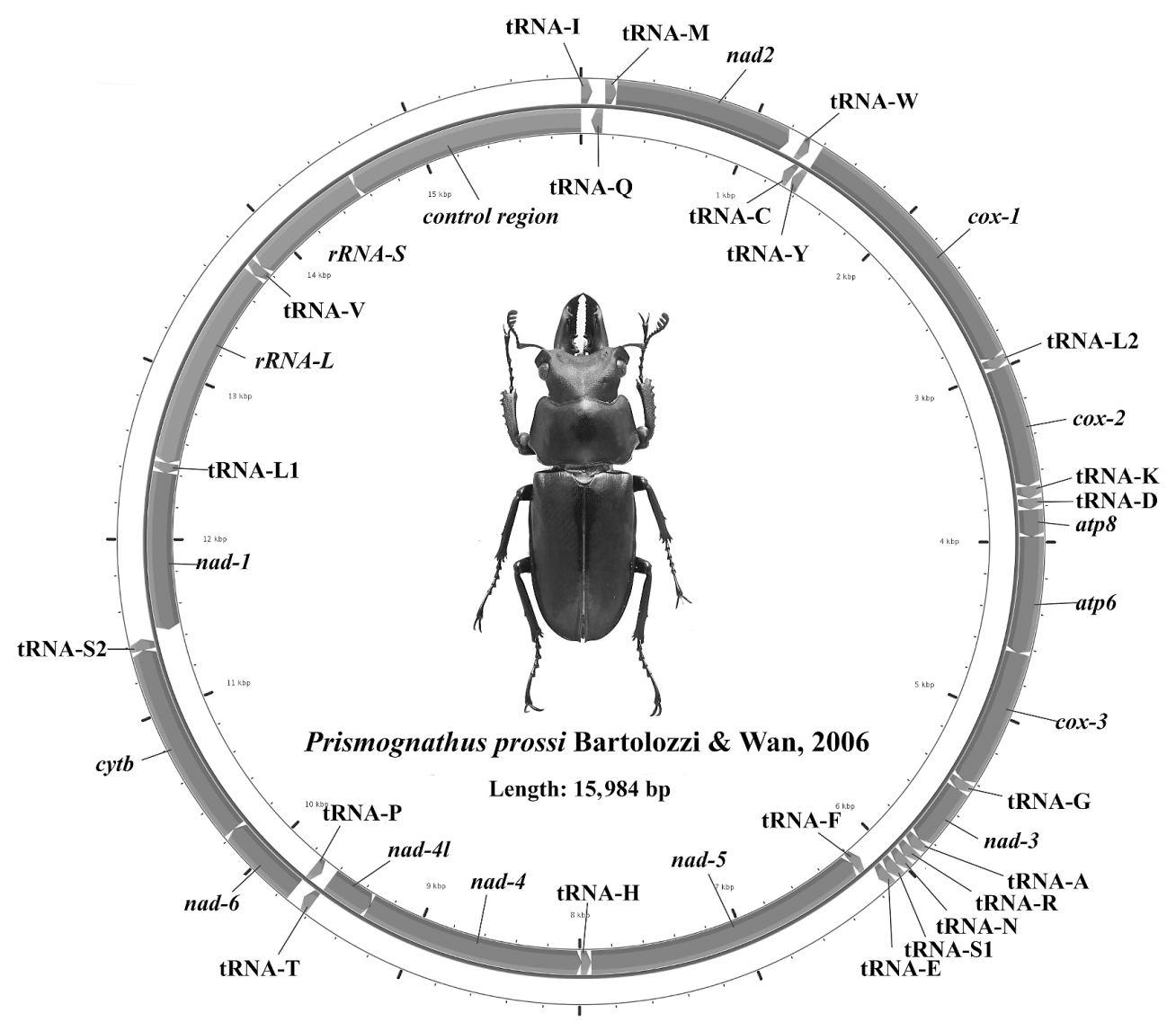

Fig. 1. Mitochondrial genome map of Prismognathus prossi. Abbreviations for the genes: cox1-3, cytochrome $\mathrm{C}$ oxidase subunits 1 to 3 ; cytb, cytochrome $\mathrm{B}$; nad1-6, NADH dehydrogenase subunits 1 to 6; atp6 and atp8, subunits 6 and 8 of ATPase; $r R N A-L$ and $r R N A-S$, ribosomal ribonucleic acid $16 S$ and 12S; tRNA A-Y, transfer ribonucleic acid A to $Y$.

were estimated through bootstrap analysis with 1,000 replications. The BI was conducted with two simultaneous Markov chain Monte Carlo runs of 2 million generations, sampled every 1,000 steps, and with the first $25 \%$ discarded as burn-in.

ML and BI phylogenies were reconstructed using a supermatrix of the 12 PCGs; only 12 of the 13 PCGs were used, because the nad2 gene of Aegus angustus was not available. Values of $\mathrm{BI} \geq$ 0.95 and $0.75 \leq \mathrm{BI}<0.95$ were considered as strong and weak support, respectively. Correspondingly, values of ML $\geq 75 \%$ were considered as strong support, values of $50 \% \leq \mathrm{ML}<75 \%$ as moderate support and $\mathrm{ML}<50 \%$ as weak support (Kim et al. 2015).

Phylogenetic trees were viewed and edited in Figtree v1.4.3 (Rambaut 2016).

\section{Results}

\subsection{Structure of mitogenome sequence of Prismognathus prossi}

The complete mitogenome of $P$. prossi (Fig. 1, Table 3, Genbank number MF614014) is 15,984 bp in length. It consists of 22 transfer RNA genes (tRNAs), two ribosomal RNA genes ( $r R N A-L$ and $r R N A-S$ ), 13 protein-coding genes (PCGs) and a control region. Four PCGs, two rRNAs and seven tRNAs are located on the N-strand; the other nine PCGs and 15 tRNAs are on the Jstrand.

The nucleotide composition of the mitogenome of $P$. prossi is $36.6 \% \mathrm{~A}, 11.6 \% \mathrm{G}, 17.6 \%$ $\mathrm{C}$ and $34.3 \% \mathrm{~T}$ with an AT content of $70.85 \%$. The sequence has both positive AT-skew (0.076) 
Table 3. Information about sequences of 22 beetle species of this study.

\begin{tabular}{|c|c|c|}
\hline Family / Tribe & Species & Genbank accession no. \\
\hline \multicolumn{3}{|l|}{ Scarabaeidae } \\
\hline Meolonthini & Rhopaea magnicornis Blackburn & FJ859903 \\
\hline Cetoniini & Protaetia brevitarsis (Lewis) & KC775706 \\
\hline Euchirini & Cheirotonus jansoni (Jordan) & KC428100 \\
\hline \multicolumn{3}{|l|}{ Lucanidae } \\
\hline Aegini & Aegus angustus Bomans & JX313668 \\
\hline Aegini & Odontolabis fallaciosa Boileau & MF908524 \\
\hline Aegini & Neolucanus perarmatus Didier & MF401425 \\
\hline Lucanini & Prismognathus prossi Bartolozzi et Wan & MF614014 \\
\hline Lucanini & Cyclommatus vitalisi Pouillaude & MF037205 \\
\hline Lucanini & Lucanus mazama (LeConte) & FJ613419 \\
\hline Lucanini & Lucanus fortunei Saunders & MF614013 \\
\hline Dorcini & Prosopocoilus gracilis (Saunders) & KP735805 \\
\hline Dorcini & Pseudorhaetus sinicus (Boileau) & KP987575 \\
\hline Dorcini & Dorcus curvidens hopei Nomura & MF612067 \\
\hline Dorcini & Dorcus parallelipipedus (Linnaeus) & JX412841 \\
\hline Dorcini & Rhaetus westwoodi (Parry) & MG159815 \\
\hline Dorcini & Macrodorcas seguyi DeLisle & MF612068 \\
\hline Dorcini & Hemisodorcus rubrofemoratus (Snellen van Vollenhoven) & JX313682 \\
\hline Dorcini & Hexarthrius vitalisi Didier & JX313676 \\
\hline Dorcini & Prosopocoilus confucius (Hope) & KU552119 \\
\hline Dorcini & Prosopocoilus blanchardi (Parry) & KF364622 \\
\hline Dorcini & Serrognathus platymelus (Saunders) & MF612070 \\
\hline Sinodendrini & Sinodendron yunnanense Král & KP735804 \\
\hline
\end{tabular}

and GC-skew (0.884). The start codon of coxl is AAT whereas the other 12 PCGs are ATN codons. Eight PCGs are stopped with TAA or TAG codons whereas the incomplete stop codons of $\mathrm{T}$ are involved in the remaining five genes. The length of all 22 tRNAs are ranging from 61 to 71 $\mathrm{bp}$, The length of the control region of $P$. prossi is $1,442 \mathrm{bp}$ with AT content of $69.56 \%$. It is located between $r R N A-S$ and $t R N A-Q$ (Fig. 1).

\subsection{Phylogenetic analysis}

As can be seen from Fig. 2, both methods yielded a similar topology indicating that $P$. prossi has an affinity with Lucanus fortunei and L. mazama (0.75 BPP / 55\% MLB), and these three species share a common ancestor with Cyclommatus vitalisi (1 BPP / 93\% MLB).

\section{Discussion}

The mitogenome of $P$. prossi has the same structure as other stag beetles (Sheffield et al. 2009, Kim et al. 2013, Wu et al. 2016, Lin et al. 2017,
Liu et al. 2017). The five genes that have incomplete stop codons of $\mathrm{T}$ in PCGs are generally found in insects and other invertebrates (Masta \& Boore 2004, Wu et al. 2014, Cheng et al. 2016). The single $t R N A-S$ lacked the cloverleaf secondary structure owing to the structure of the dihydrouridine (DHU) arm, which is also in accordance with previous studies (Cameron 2014).

The phylogenetic analyses suggest that $P$. prossi is related to L. mazama and L. fortunei and this triplet has a common ancestor with $C$. vitalisi. These phylogenetic analyses are consistent with the studies inferred from multi-genes including COI, 16S rDNA, Cytb, ITS2 and EF1-a (Kim \& Farrell 2015, Wu \& Wan 2016). Due to the inadequate taxa sampling, however, this study cannot explore the affinity of $P$. pross $i$ with other taxa conclusively, and thus information about more taxa are required in order to establish the definite phylogenetic relationships of Lucanidae.

Acknowledgments. We are thankful to Yun-fei Wu for the donation of fresh specimens, to Dr. Hu Li and Dr. Fan Song (Department of Entomology, China Agricultural University) for giving us advice about data analysis. We also want to express our gratitude to the lab colleagues for their kind 


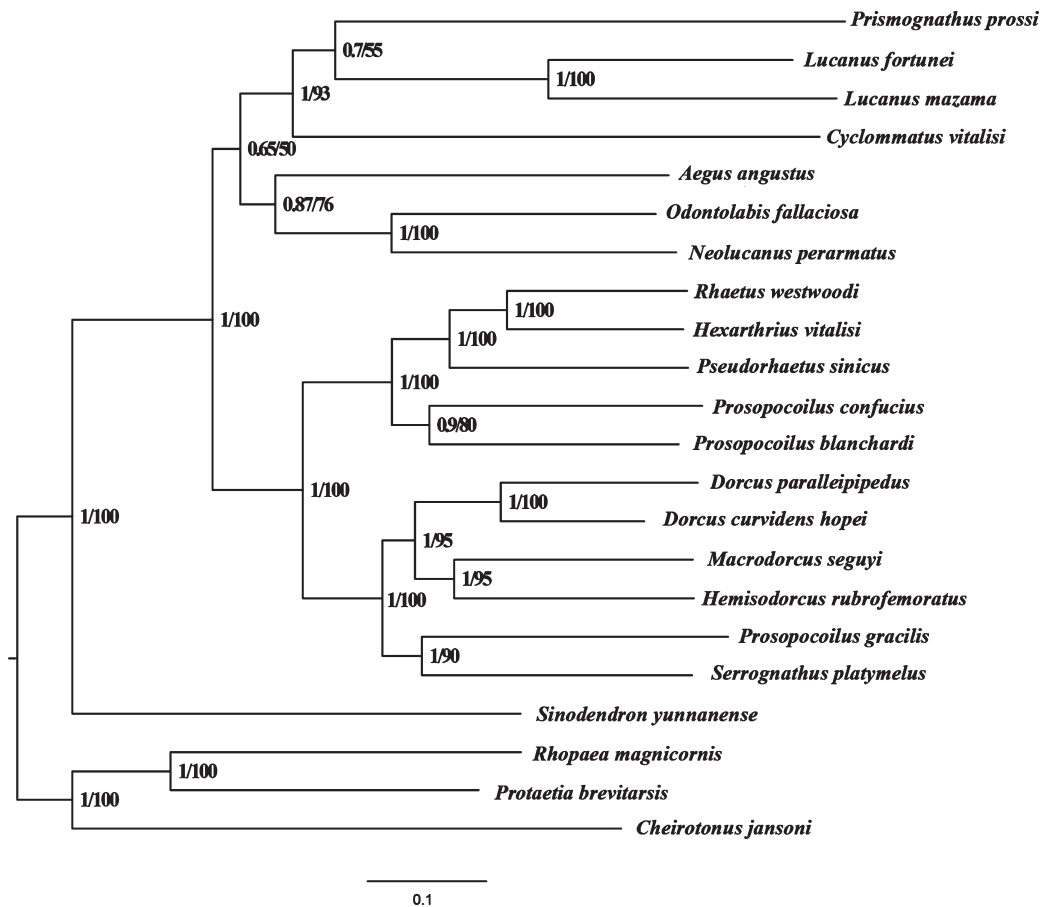

Fig. 2. Topology based on Maximum likelihood inference (ML, bootstrap values to right of each slash) based on 12 of the 13 protein-coding genes (for Aegus angustus, nad2 was not available) of Prismognathus prossi and 18 other lucanids with three scarab species (Rhopaea magnicornis, Protaetia brevitarsis and Cheirotonus jansoni) as outgroups. Bayesian inference (BI, posterior probabilities to left of each slash) produced a similar topology. The line with 0.1 is a scale for scaled branches and shows the evolutionary distance of each species.

help. We thank the National Natural Science Foundation of China (grants No. 31201745, No. 31071954, and No. 31572311) for providing the funding for this study. We thank the reviewers for their kind suggestions for improving the manuscript.

\section{References}

Balke, M., Ribera, I. \& Vogler, A. P. 2004: MtDNA phylogeny and biogeography of Copelatinae, a highly diverse group of tropical diving beetles (Dytiscidae). Molecular Phylogenetics and Evolution 32: 866-880. doi: https://doi.org/10.1016/j.ympev.2004.03.014

Bartolozzi, L. \& Wan, X. 2006: A new species of Prismognathus Motschulsky from Xizang (Tibet), China. Zootaxa 1129: 61-68. doi: https://doi.org/10.11646/ zootaxa.1129.1.5

Breeschoten, T., Doorenweerd, C., Tarasov, S. \& Vogler, A. P. 2016: Phylogenetics and biogeography of the dung beetle genus Onthophagus inferred from mitochondrial genomes. - Molecular Phylogenetics and Evolution 105: 86-95. doi: https://doi.org/10.1016/ j.ympev.2016.08.016

Cameron, S. L. 2014: Insect mitochondrial genomics: Implication for evolution and phylogeny. - Annual Re- view of Entomology 59(1): 95-117. doi: https:// doi.org/10.1146/annurev-ento-011613-162007

Cheng, X. F., Zhang, L. P., Yu, D. N., Storey, K. B. \& Zhang, J. Y. 2016: The complete mitochondrial genomes of four cockroaches (Insecta: Blattodea) and phylogenetic analyses within cockroaches. - Gene 586(1): 115-122. doi: https://doi.org/10.1016/j.gene. 2016.03.057

Crampton-Platt, A., Timmermans, M. J. T. N., Gimmel, M. L., Kutty, S. N., Cockerill, T. D., Khen, C. V. \& Vogler, A. P. 2015: Soup to tree: the phylogeny of beetles inferred by mitochondrial metagenomics of a Bornean rainforest sample. - Molecular Biology and Evolution 32(9): 2302-16. doi: https://doi.org/10.1093/molbev/msv111

Fujita, H. 2010: The lucanid beetles of the world. Mushi-Sha, Japan. 488 pp., 248 pls.

Gillett, C. P., Crampton-Platt, A., Timmermans, M. J., Jordal, B. H., Emerson, B. C. \& Vogler, A. P. 2014: Bulk de novo mitogenome assembly from pooled total DNA elucidates the phylogeny of weevils (Coleoptera: Curculionoidea). - Molecular Biology and Evolution 31(8): 2223-2237. doi: https://doi.org/10.1093/ molbev/msu154

Grant, J. R. \& Stothard, P. 2008: The CGView Server: a 
comparative genomics tool for circular genomes. Nucleic Acids Research 36: 181-184. doi: https:// doi.org/10.1093/nar/gkn179

Hosoya, T., Honda, M. \& Araya, K. 2001: Genetic variations of 16S rRNA gene observed in Ceruchus lignarius and Dorcus rectus rectus (Coleoptera: Lucanidae). — Entomological Science 4: 335-344.

Huang, H. \& Chen, C. C. 2017: Stag beetles of China III. - Formosa Ecological Company, Taiwan. 524 pp.

Huelsenbeck, J. P. \& Ronquist, F. R. 2003: MrBayes: A Program for the Bayesian inference of phylogeny. Bioinformatics 17: 754-755. doi: https://doi.org/ 10.1093/bioinformatics/17.8.754

Kim, M. J., Kim, K. G., Kim, S. R. \& Kim, I. 2013: Complete mitochondrial genome of the two-spotted stag beetle, Metopodontus blanchardi (Coleoptera: Lucanidae). - Mitochondrial DNA 26(2): 307-309. doi: https://doi.org/10.3109/19401736.2013.825788

Kim, S. I. \& Farrell, B. D. 2015: Phylogeny of world stag beetles (Coleoptera: Lucanidae) reveals a Gondwanan origin of Darwin's stag beetle. - Molecular Phylogenetics and Evolution 86: 35-48. doi: https://doi.org/ 10.1016/j.ympev.2015.02.015

López-López, A. \& Vogler, A. P. 2017: The mitogenome phylogeny of Adephaga (Coleoptera). - Molecular Phylogenetics and Evolution 114: 166-174. doi: https://doi.org/10.1016/j.ympev.2017.06.009

Li., H., Leavengood, J. M. Jr, Chapman, E. G., Burkhardt, D., Song, F., Jiang, P., Liu, J. P., Zhou, X. G. \& Cai, W. Z. 2017: Mitochondrial phylogenomics of Hemiptera reveals adaptive innovations driving the diversification of true bugs. - Proceedings of the Royal Society B Biological Sciences 284(1862). doi: https://doi.org/ 10.1098/rspb.2017.1223

Lin, Z. Q., Song, F., Li, T., Wu, Y. Y. \& Wan, X. 2017: New mitogenomes of two Chinese stag beetles (Coleoptera, Lucanidae) and their implications for systematics. Journal of Insect Science 17(2): 63. doi: https:// doi.org/10.1093/jisesa/iex041

Liu, J., Li, C. G., Zhou, S. J. \& Wan, X. 2017: The first complete mitogenome of Cyclommatus stag beetles (Coleoptera: Lucanidae) with the phylogenetic implications. - Entomotaxonomia 39: 294-299.

Liu, Y., Song, F., Jiang, P., Wilson, J. J., Cai, W. Z. \& Li, H. 2017: Compositional heterogeneity in true bug mitochondrial phylogenomics. - Molecular Phylogenetics and Evolution 118: 135-144. doi: https://doi.org/ 10.1016/j.ympev.2017.09.025

Masta, S. E. \& Boore, J. L. 2004: The complete mitochondrial genome sequence of the spider Habronattus oregonensis reveals rearranged and extremely truncated tRNAs. - Molecular Biology and Evolution 21(5): 893-902. doi: https://doi.org/10.1093/molbev/msh 096

Perna, N. T. \& Kocher, T. D. 1995: Patterns of nucleotide composition at fourfold degenerate sites of animal mitochondrial genomes. - Journal of Molecular Evolution 41(3): 353-358. doi: https://doi.org/10.1007/ BF01215182
Posada, D. 2008: jModelTest: Phylogenetic model averaging. - Molecular Biology \& Evolution 25: 1253 1256. doi: https://doi.org/10.1093/molbev/msn083

Rambaut, A. 2016: FigTree: Tree Figure Drawing Tool, Version 1.4.3. - University of Edinburgh, http:// tree.bio.ed.ac.uk/.

Sheffield, N. C., Song, H. J., Cameron, S. L. \& Whiting, M. F. 2009: No stationary evolution and compositional heterogeneity in beetle mitochondrial phylogenomics. - Systematic Biology 58(4): 381-394. doi: https://doi.org/10.1093/sysbio/syp037

Simon, C., Frati, F., Beckenbach, A., Crespi, B., Liu, H. \& Flook, P. 1994: Evolution, weighting, and phylogenetic utility of mitochondrial gene sequences and a compilation of conserved polymerase chain reaction primers. - Annals of the Entomological Society of America 87: 651-701. doi: https://doi.org/10.1093/ae$\mathrm{sa} / 87.6 .651$

Stamatakis, A. 2014: RAxML version 8: a tool for phylogenetic analysis and post-analysis of large phylogenies. - Bioinformatics 30: 1312-1313. doi:https:// doi.org/ 10.1093/bioinformatics/btu033

Tamura, K., Stecher, G., Peterson, D., Filipski, A. \& Kumar, S. 2013: MEGA6: molecular evolutionary genetics analysis version 6.0. - Molecular Biology and Evolution 30: 2725-2729. doi: https://doi.org/ 10.1093/molbev/mst197

Timmermans, M. J. T. N., Barton, C., Haran, J., Ahrens, D., Culverwell, C. L., Ollikainen, A., Dodsworth, S., Foster, P. G., Bocak, L. \& Vogler A. P. 2016: Familylevel sampling of mitochondrial genomes in Coleoptera: Compositional heterogeneity and phylogenetics. - Genome Biology and Evolution 8(1): 161-175. doi: https://doi.org/10.1093/gbe/evv241

Wan, X \& Yang, X. K. 2007: Study on the Systematics of Lucanidae (Coleoptera: Scarabaeoidea). - Institute of Zoology, Chinese Academy of Sciences, Beijing. $421 \mathrm{pp}$.

Wu, Q. L., Li, Q., Gu, Y., Shi, B. C., Achterberg, C., Wei, S. J. \& Chen, X. X. 2014: The complete mitochondrial genome of Taeniogonalos taihorina (Bischoff) (Hymenoptera: Trigonalyidae) reveals a novel gene rearrangement pattern in the Hymenoptera. - Gene 543: 76-84. doi: https://doi.org/10.1016/j.gene.2014.04. 003

Wu, Y. Y., Cao, Y. Y., Fang, J. \& Wan, X. 2016: The first complete mitochondrial genome of stag beetle from China, Prosopocoilus gracilis (Coleoptera, Lucanidae). - Mitochondrial DNA 27(4): 2633. doi: https://doi.org/10.3109/19401736.2015.1041129

Wu, Y. Y. \& Wan, X. 2016: Molecular phylogeny of Lucanidae from China (Coleoptera: Scarabaeoidea). Anhui University, Anhui, China. 83 pp.

Yuan, M. L., Zhang, Q. L., Zhang, L., Guo, Z. L., Liu, Y. J., Shen, Y. Y. \& Shao, R. 2016: High-level phylogeny of the Coleoptera inferred with mitochondrial genome sequences. - Molecular Phylogenetics and Evolution 104: 99-111. doi: https://doi.org/10.1016/j.ympev. 2016.08.002 